University of Nebraska - Lincoln

DigitalCommons@University of Nebraska - Lincoln

Civil and Environmental Engineering Faculty

Publications

Civil and Environmental Engineering

2008

\title{
Assimilating Remote Sensing-Based ET into SWAP Model for Improved Estimation of Hydrological Predictions
}

\author{
Baburao Kamble \\ University of Nebraska-Lincoln, bkamble3@unl.edu
}

Ayse Kilic

University of Nebraska-Lincoln, akilic@unl.edu

Follow this and additional works at: https://digitalcommons.unl.edu/civilengfacpub

Part of the Civil Engineering Commons

Kamble, Baburao and Kilic, Ayse, "Assimilating Remote Sensing-Based ET into SWAP Model for Improved Estimation of Hydrological Predictions" (2008). Civil and Environmental Engineering Faculty Publications. 38.

https://digitalcommons.unl.edu/civilengfacpub/38

This Article is brought to you for free and open access by the Civil and Environmental Engineering at DigitalCommons@University of Nebraska - Lincoln. It has been accepted for inclusion in Civil and Environmental Engineering Faculty Publications by an authorized administrator of DigitalCommons@University of Nebraska Lincoln. 


\title{
Assimilating Remote Sensing-Based ET into SWAP Model for Improved Estimation of Hydrological Predictions
}

\author{
Baburao Kamble $e^{1,2}$, Ayse Irmak ${ }^{1}$ \\ ${ }^{1}$ Department of Civil Engineering, University of Nebraska-Lincoln, Lincoln, NE 68503, USA \\ ${ }^{2}$ Member IEEE
}

\begin{abstract}
An agro-hydrological simulation model is useful for agriculture monitoring and Remote Sensing provides useful information over large area. Combining both information by data assimilation is used in agro-hydrological modeling and predictions, where multiple remotely sensed data, ground measurement data and model forecast routinely combined in operational mapping procedures. Remote sensing cannot observe input parameters of agro-hydrological models directly. A method to estimate input parameters of such model from Remote Sensing using data assimilation has been proposed by Ines [2002] using the SWAP (Soil, Water, Atmosphere and Plant) model. A Genetic Algorithm (GA) loaded stochastic physically based soil-water-atmosphere-plant model (SWAP) was extended for the discussed problem and used in the study. The objective of this study was to implement a data assimilation scheme to estimate hydrological parameters (e.g soil moisture) of SWAP model. For this study six Landsat TM/ETM satellite images were obtained for part of the Great Plains (Path 29, Row 32) in the states of Nebraska (NE) for the 2006 growing season (May -October). Then a land surface energy balance model (METRIC) was used to map spatiotemporal distribution of evapotranspiration. The ability of METRIC accuracy was compared with the measurements at several flux sites with Bowen Ratio Energy Balance System units. Remotely sensed ET data and ground measurement data from experiment fields were then combined in a data assimilation to estimate parameters of the SWAP model. The system is initialized with a population of random solutions and searches for optima by updating generations. The result shows that the reasonable parameters (sowing date and harvesting date, Ground water level) were successfully estimated. On the basis of estimated parameters, soil moisture is predicted by SWAP model. The agro-hydrological model driven by the observed ET produces reasonable water cycle states and fluxes, and the estimates are moderately improved by assimilating ET measurements that provides information on the surface soil moisture state, while it remains challenging to improve the results by assimilating regional ET estimated from satellite-based measurements.
\end{abstract}

Keywords: Genetic algorithm, Data Assimilation, Remote Sensing, METRIC, Evapotranspiration, Hydrological Modeling, SWAP

\section{INTRODUCTION}

A ccurate estimation of evapotranspiration (ET) plays an important role in quantification of the water balance at the pixel, watershed, basin and regional scale for better planning and managing water resources (Irmak et al., 2008a). Unfortunately, ET estimation under actual field conditions is still a very challenging task for scientists and water managers (Kamble et al, 2007). Furthermore, quantification of ET at multiple scales is spatially restricted because in-situ observations provide only point measurements. Techniques such as bowen ratio energy balance system and eddy correlation measure ET on a field scale. These systems may not be practical when quantifying water use at watershed or larger scale. Remote sensing techniques have emerged as a very useful tool to provide such information at various temporal and spatial scales (Courault et al. 2003). ET estimated from remote sensing observations can be used to calibrate hydrology model or estimate uncertain model parameters in the model via data assimilation.

With advances in remote sensing in recent years, there has been an increasing attention on estimating uncertain model parameters from remote sensing observations via data assimilation. Benard et al. [1981] demonstrated that evaporation could be modeled very accurately with the contribution of surface moisture measurements every 3 days. Prevot et al. [1984] continued this work and showed that the soil water balance could be determined with equal accuracy using remotely sensed surface soil moisture estimates substituted for in situ observations. Ines and Honda [2002] developed an assimilation methodology of the SWAP (Soil,
Water, Atmosphere, Plant) crop model with RS data using Genetic Algorithm (GA). Similar works by Ines [2003], Srinuandee [2005], Chemin [2005], Kamble[2006], Kulkarni [2006], Thapa [2006] used remotely sensed information combined with a binary GA and SWAP model for optimizing soil hydraulic parameters. Furthermore, Kamble [2006] implemented SWAP-GA model (Modified SWAP-GA) with a new methodology to assimilate RS evapotranspiration (ETa) data for satellite images by MODIS for Sirsa Irrigation Circle-Haryana India.

In this study, METRIC model was first used to map spatiotemporal distribution of ET in Nebraska. We have then combined METRIC-derived ET with a SWAP model Genetic Algorithm to (1) update and correct SWAP ET estimations at the field level and (2) assess its impact on scheme water use. Additionally, we show here that such ET estimates may be used together with on-farm measurements of applied irrigation water to provide reliable estimates of soil moisture.

\section{STUDY AREA}

The study was conducted at the South-central Nebraska. The long-term average rainfall in south central part of the state is about $680 \mathrm{~mm}$ although the annual total rainfall shows significant variations from year to year (e.g., $420 \mathrm{~mm}$ in 1988 to $1,040 \mathrm{~mm}$ in 1993). The dominant cropping system in south central Nebraska is corn-soybean rotation with increasing continuous corn production as the demand for ethanol production has been increasing. Most of the croplands in the region are irrigated with center pivots with the ground water pumped from the Ogallala aquifer being the dominant water supply for irrigation. The weather data used in this study were 
measured with an automated weather station operated by the High Plains Regional Climate Center (http://www.hprcc.unl.edu).

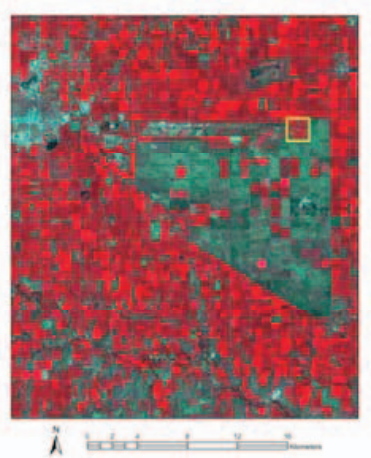

Fig. 1. Study area: South Central Agricultural Laboratory near Clay Center, Nebraska

\section{METHODOLOGY}

\section{A. Evapotranspiration monitoring with METRIC}

The landsat TM/ETM satellite images were obtained for part of the Great Plains in the states of Nebraska (Path 29, Row 32) for the 2006 growing season (May -October). The hourly in situ meteorological observational data were acquired from South Central Agricultural Laboratory (SCAL) of the University of Nebraska-Lincoln located near Clay Center, NE. A total of 6 cloud free images from May through October were processed to calculate ET. The hourly in situ energy flux observational data were acquired from South Central Agricultural Laboratory (SCAL) research farm of University of Nebraska located at Clay Center. The energy flux data were measured using Bowen Ratio Energy Balance System (Irmak et al., 2006) and were used for METRIC model.

\section{B. SWAP-GA Model Framework}

Genetic algorithm used in this research comprises of three components that are Remote sensing, SWAP model and Genetic algorithm. Ines [2002] has proposed a data assimilation scheme using GA as an optimizer. This process is termed as SWAP-GA method. We used SWAP-GA to estimate starting date of cropping, irrigation scheduling start time, time extent of cropping and the groundwater depths. The newly proposed parameters were fed to SWAP by GA according to the evaluation of the difference processes between SWAP output ETa values and the target ETa values.

Consider $\mathrm{C}$ the cost function, having $(\mathrm{x}, \mathrm{y}, \mathrm{d})$ parameters, $x$ the longitude $[0-180 / E-W], y$ the latitude $[0-90 / N-S], d$ the date [yyyymmdd] . With $\mathrm{d}=[\mathrm{i}, \ldots, \mathrm{j}]$, with $\mathrm{i}$ to $\mathrm{j}$ being the different satellite overpass dates, $n$ is the sum of $i$ to $j$.

$$
C_{x y}=\frac{1}{n} \sum_{i}^{j}\left|E T a_{x y d}-E T a_{S W A P_{x y d}}\right| \mathrm{mm}
$$

Where $E T a_{x y d}$ is the measured ET from RS at time $\mathrm{t}$; $\mathrm{n}$ the time domain; $\mathrm{C}_{\mathrm{xy}}$ is the objective function. The environment pressure is the SWAP model ETa output that has to match the remote sensing ETa target. When a minimum-difference defined threshold will be reached, SWAP parameters will be stored for reconstruction of high spatial ETa for any required day in the cropping season.

The fitness of an individual having xy pixel location characteristics is the inverse of the cost function times the constraints aiming at minimizing the differences between SWAP simulation and target ETa.

$$
F_{x y}=\frac{1}{\left(C_{x y} *(1.0+\text { Constraint })\right)}
$$

The constraint is function of date of emergence of first crop and the date of emergence of second crop.

Constraint $=365-D E C$ doy $21-140$

Subject to: Possible range of sowing dates:

$$
b_{\min } \leq s d_{j} \leq b_{\max j} \quad(\mathrm{j}=1, \ldots, 6)
$$

\section{RESUlts AND DisCUSSION}

\section{A. Evapotranspiration monitoring with METRIC}

Figure 2 shows ET map corresponding to the 2006 season for the entire Clay, York, Hamilton Adams and Fillmore counties in NE. The study site SCAL is located in Clay county at latitude $40^{\circ} 34^{\prime}$, longitude $98^{\circ} 08^{\prime}$. ET map resolution is $30 \times 30 \mathrm{~m}$ and the range is $400 \mathrm{~mm} / \mathrm{season}$ (bare soil) to $950 \mathrm{~mm} / \mathrm{season}$ (irrigated crops). Seasonal ET varied from $950 \mathrm{~mm}$ for well-irrigated fields to $400 \mathrm{~mm}$ for nonagricultural areas. Rain fed areas surrounding the Fillmore (in the south east) had ET values around $400 \mathrm{~mm}$ which depicted the bare fields and fallow lands, the ET over Adams county shows the mixed ET in between $400 \mathrm{~mm}$ to $650 \mathrm{~mm}$, while ET values are for the SCAL fields located towards the south in York and Hamilton county due to shallow water table, lateral seepage from the SCAL fields and a open network of irrigation canals. The ET map further shows a spatial gradient of increasing ET from the Southern parts towards the Northern parts of the irrigation system except low ET in the Howard due to settlements. All of these ET values are important for the agro-hydrological balance of the area as well as ground water modeling.

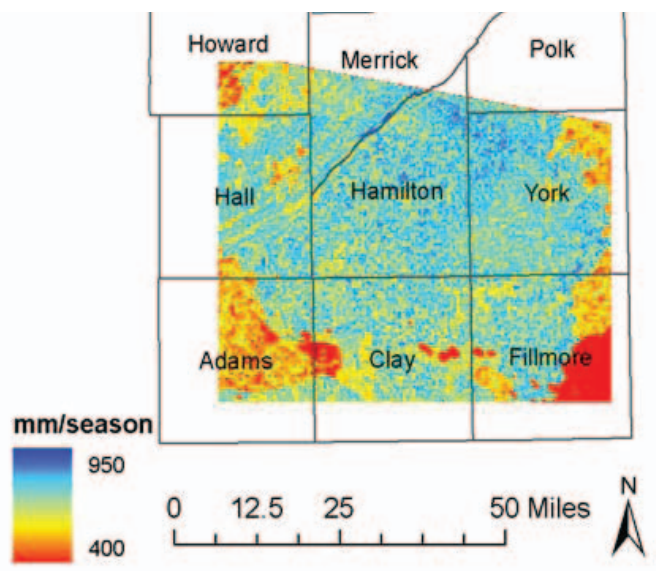

Fig. 2. Spatial distribution of remotely sensed Evapotranspiration from Landsat ETM+ for the 2006 


\begin{tabular}{|c|c|}
\hline Date & $E T$ \\
\hline $22 / 05 / 2006$ & 0.095 \\
\hline $23 / 06 / 2006$ & 0.58 \\
\hline $17 / 07 / 2006$ & 0.75 \\
\hline $25 / 07 / 2006$ & 0.71 \\
\hline $19 / 09 / 2006$ & 0.24 \\
\hline $13 / 10 / 2006$ & 0.18 \\
\hline
\end{tabular}

Table 1: Remotely sensed Evapotranspiration to satellite overpass dates

According to table 1, average daily ET (ET24) was $0.426 \mathrm{~cm}$ $\mathrm{d}^{-1}$ with a mode and maximum values of 0.75 and $0.71 \mathrm{~cm} \mathrm{~d}^{-1}$, respectively, for the study field. It is evident from the numerical figures in table that some crops are still developing on May and others are transpiring at higher rates. On June23, all the crops in the area are established. This indicates the variability of sowing dates and water management practices as influenced by water availability.

\section{B. Remotely sensed Evapotranspiration Data Assimilation}

In simulations, hydraulic properties were based on measured values where possible; some values were altered slightly by optimizing the model to the local conditions until good agreement with measured ET was attained. Given these constraints, it was not possible to achieve perfect agreement with measurements for the wide range of ET conditions that occurred during the study. The objective of assimilation is to obtain the best estimate of the state of the system by combining observations with the forecast model first guess. ET data from METRIC model were used as the "observed" RS data for the investigated pixel. Above results showed good fitness between the observed and simulated ET. As expected, there is bias due to the comparison of point observation with model. Some of this bias could be attributed to uncertainty in SWAP model parameters.

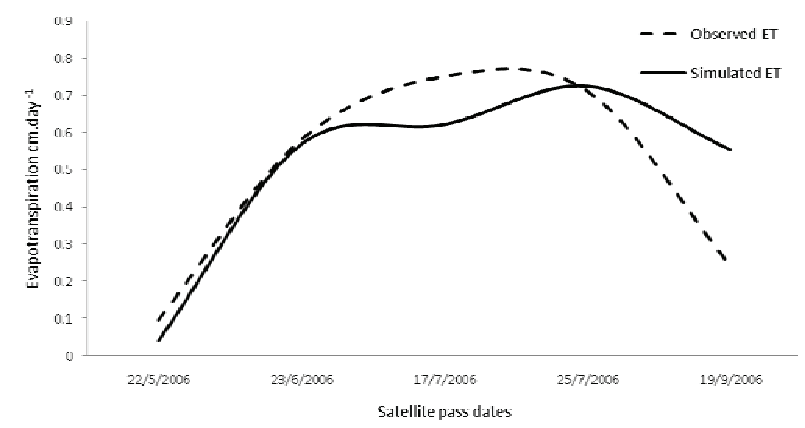

Fig. 3. Results of Actual Evapotranspiration Simulated (ETa from SWAP) and Observed (ETa from Remote Sensing) in SWAPGA model

Overall, the ET data assimilation results (figure 3) indicated that SWAP-GA performs well for the advective conditions of the study area with prediction errors of $10-20 \%$. Some errors in the evaluation may have been introduced by the hydraulic parameters. According to Wright and Jensen (1978), a common standard error for ET prediction equations based on weather data using Penman or Penman-Monteith type equations is as much as $10 \%$ of daily estimates.

\section{Optimization of crop growth parameters from Data Assimilation}

The goal of the calibration process is to find optimal sets of configuration parameters for SWAP models. Optimal configuration parameters are determined by comparing the RMSE of the derived parameters, the convergence, the amount of a priori information used. The RMSE and Square of correlation coefficient then calculated from the observed and optimized values (Table 2). Good agreement was found between the optimized and observed ET. RMSE and r2 improvements occurred with the observed data when generation and population increased from 10 Generation 10 Population to 100 Generation and 100 Population.

\begin{tabular}{|c|c|c|}
\hline & $\left(\mathrm{r}^{2}\right)$ & RMSE $(\mathrm{mm})$ \\
\hline 10Gen10Pop & 0.86 & 7.28 \\
\hline 50Gen50Pop & 0.22 & 10.808 \\
\hline 100Gen100Pop & 0.962 & 3.94 \\
\hline 500Gen500Pop & 0.96 & 5.38 \\
\hline Avg Gen Avg Pop & 0.97 & 3.21 \\
\hline
\end{tabular}

Table 2: Remotely sensed Evapotranspiration to satellite overpass dates

\section{Soil Moisture Estimation from Data Assimilation}

Soil-based measurements may be a far more practical and easy method for corn growers to use to schedule irrigations and assess current irrigation practices. Figure 6 shows soil moisture content in $\mathrm{cm}^{3} / \mathrm{cm}^{3}$ from January-2006 to December 2006 obtained from SWAP-GA data assimilation for effective irrigation management and illustrates how readings typically fluctuate from spring through corn harvesting. At the start of the season the soil is moist from winter and spring rains; the readings are less than $0.3 \mathrm{~cm}^{3} / \mathrm{cm}^{3}$. Gradually the soil dries and the readings increase, beginning with the simulation at $0.5,9.5,27.5,52.5 \mathrm{~cm}$. The uppermost 0.5 and 9.5 reading normally climbed first, as there was greater root activity in the upper portion of the soil profile than at deeper depths. Furthermore, moisture readings at the 27.5 and $52.5 \mathrm{~cm}$ depth were typically lower (more soil moisture) and fluctuated far less than the shallow depths. When the soil moisture content dropped to near 80 in late March, rainfall started and the soil moisture readings at all four depths went to above 0.3 , indicating the soil profile had been refilled. The drying cycle resumed until a partial irrigation occurred in early May. The reason for the partial irrigation was that it was needed to replenish enough soil moisture to sow the crop through the germination process without excessive soil moisture depletion and crop stress.

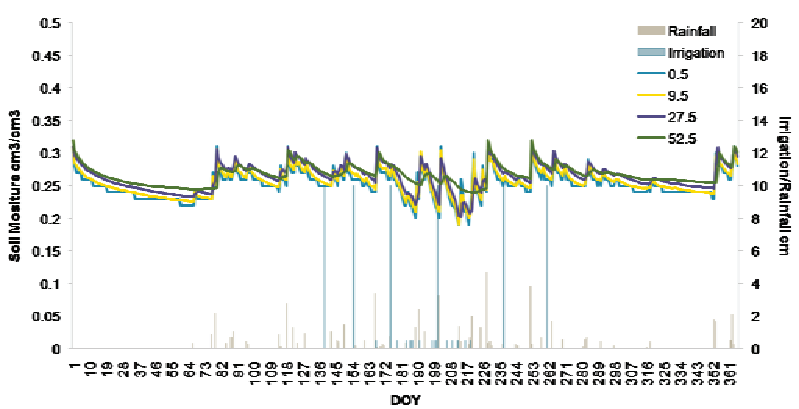

Fig. 3. Results of Actual Evapotranspiration Simulated (ETa from SWAP) and Observed (ETa from Remote Sensing) in SWAPGA model 


\section{CONCLUSION}

This study used remote sensing data to characterize system via a GA based hydrological data assimilation approach in Great Plain environment, and then the derived data were used as inputs to our water management optimization model. Reasonable parameters were successfully estimated and the ETa output from SWAP model matched with the actual ETa reasonably well. Although the analyses were limited to the conditions imposed in the water management optimization model, some basic but useful findings have been drawn on how to make use to the best possible way the limited soil moisture estimation and best possible utilization of maximum irrigation water. Soil moisture in the unsaturated zone in study area responded strongly to rainfall events because of the shallow water table in the great plain and additional net inputs from lateral saturated subsurface flows. Short drought episodes also occurred in rainfall events January to march, even causing short-term water stress in the relatively dry low areas. In most real applications, the model needs to be evaluated (i.e., given a parameter set, compute a synthetic dataset and its associated goodness of fit) a great many times. If this evaluation is computationally expensive, the forward modeling approach can become impractical. GA-based optimization retains the advantageous features of forward modeling, while reducing the number of required function evaluations to a level that is often much more computationally manageable. These conclusions suggest that it is indeed necessary to couple a remotely sensed ET with a pixel-based hydrological model in order to study and explore the water management options.

\section{REFERENCES}

[1] A.V.M. Ines, K. Honda, "On quantifying agricultural and wate management practices from low spatial resolution RS data using genetic algorithms: A numerical study for mixed pixel environment," Advances in Water Resources, vol. 28, pp856-870, 2005.

[2] Allen, R.G., L.S. Pereira, D. Raes, and M. Smith. (1998). Crop evapotranspiration. Guidelines for computing crop water requirements. FAO Irrig. and Drain. Paper No. 56. Rome, Italy. 300 pp.

[3] Bastiaanssen, W. G. M., Menenti, M., Feddes, R. A., and Holtslag, A. A. M. (1998). "A remote sensing surface energy balance algorithm for land (SEBAL): 1. Formulation.” J. Hydrol., 212-213, 198-213.

[4] Bénard, C. (1981). "Experimental Results of a Latent-Heat Solar-Roof, Used for Breeding Chickens". Solar Energy 26 (4): 347-359. doi:doi:10.1016/0038-092X(81)90181-X

[5] Churkina, G., Running, S.W., Schloss, A.L., the participants of the Potsdam NPP model intercomparison, 1999. Comparing global models of terrestrial Net Primary Productivity (NPP): the importance of water availability. Global Change Biol. 5(Suppl. 1), 46-55.

[6] Courault D, Lacarrere P, Clastre P, Lecharpentier P, Jacob F, Marloie O, Prévot L et Olioso A, 2003. Estimation of surface fluxes in a small agricultural area using the three-dimensional atmospheric model meso$\mathrm{NH}$ and remote sensing data. Canadian Journal of Remote Sensing 29 (6): 741-754

[7] Errico, R.M., G. Ohring, J. Derber, and J. Joiner, 2000: Meeting summary. NOAA-NASA-DoD workshop on satellite data assimilation. Bull. Amer. Meteor. Soc., 81, 2457-2462.

[8] Doorenbos, J., and W.O. Pruitt. (1977). Guidelines for prediction of crop water requirements. FAO Irrig. and Drain. Paper No. 24 (revised), Rome, Italy. 144 pp.

[9] Brubaker, K. L., D. Entekhabi and P. S. Eagleson, 1993: Estimation of continental precipitation recycling, Journal of Climate, 6(6), 1077-1089.

[10] Eagleson, 1970 P.S. Eagleson, Dynamic hydrology, McGraw-Hill, New York (1970).
[11] Eitzinger, J., Z. Žalud, C.A.M. Van Diepen, M. Trnka, D. Semerádová, M. Dubrovský and M. Oberforster, 2000: Calibration and evaluation of the WOFOST model for

[12] Engman, Editors, Remote Sensing in Hydrology and Water Management (2000), pp. 197-216.

[13] Galantowicz et al., 1998 J.F. Galantowicz, D. Entekhabi and E.G Njoku, Tests of sequential data assimilation for retrieving profile soil moisture and temperature from observed L band radiobrightness, IEEE Trans. Geosci. Remote Sensing 37 (1998) (4), pp. 1860-1870.

[14] Goldberg, 1989 D.E. Goldberg, Genetic algorithms for search, Optimization and Machine Learning, Addison-Wesley Publishing Co. Reading, Mass (1989).

[15] Holland, 1975 J.H. Holland, Adaptation in Natural and Artificial

[16] Houser P. R., W. J. Shuttleworth, J. S. Famiglietti, H. V. Gupta, K. H. Syed, and D. C. Goodrich, 1998: Integration of soil moisture remote sensing and hydrologic modeling using data assimilation. Water Resour. Res, 34, 3405-3420.

[17] Irmak, A., S. Irmak, and D.L. Martin, 2007, "Reference and crop evapotranspiration in south central Nebraska: I. Comparison and analysis of grass and alfalfa-reference evapotranspiration," Journal of Irrigation and Drainage Engineering

[18] Kamble, B.,Evapotranspiration Data Assimilation with Genetic Algorithms and SWAP Model for On-Demand Irrigation, M.Engg Thesis, Asian Institute of Technology, Thailand, 2006

[19] Kroes, J.G., Wesseling, J.G, Van Dam, J.C. (2000). Integrated modeling of the soil-water-atmosphere-plant system using the model SWAP 2.0 an overview of theory and an application. Hydrological Processes, 14, 1993-2002.

[20] Prevot, L., R. Bernard, O. Taconet, D. Vidal-Madjar, and J.L. Thony. 1984. Evaporation from a bare soil evaluated using a soil water transfer model and remotely sensed surface soil moisture data. Water Resour. Res. 20:311-316.

[21] Reichle R. H., D. Entekhabi, and D. B. McLaughlin, 2001: Downscaling of radiobrightness measurements for soil moisture estimation: A fourdimensional variational data assimilation approach. Water Resour. Res. 37, 2353-2364.

[22] Rhodin A., F. Kucharski, U. Callies, D. P. Eppel, and W. Wergen, 1999: Variational analysis of effective soil moisture from screen-leve atmospheric parameters: Application to a short-range weather forecast model. Quart. J. Roy. Meteor. Soc., 125, 2427-2448

[23] Y.Chemin \& K.Honda.,(2005).Spatio-temporal fusion of rice actua evapotranspiration with genetic algorithm and agro-hydrological model. TGRS-2006

[24] Z wart, S.J. and W.G.M. Bastiaanssen, 2003. Review of measured crop water productivity values forirrigated wheat, rice, cotton and maize. Agric. Water Manage. 69(2): 115-133. 